\title{
EFEITO DA DENSIDADE POPULACIONAL E ARRANJOS DE PLANTIO NA PRODUÇÃO DE AMENDOIM IAC 503 E IAC OL3
}

Everton Luís Finoto; Guilherme Xavier Lúcio dos $\mathrm{Santos}^{2}$; Paulo Sérgio Cordeiro Junior³ Rogério Soares de Freitas4; Ignácio José Godoy ${ }^{5}$

1Engenheiro Agrônomo, Bolsista de Aperfeiçoamento Técnico Fundag, APTA, guilhermexaviersantos@hotmail.com; [2Engenheiro Agrônomo, Bolsista de Aperfeiçoamento Técnico Fundag, APTA; ${ }^{3}$ Engenheiro Agrônomo, mestrando em Produção Vegetal UNESP/FCAV; ${ }^{4}$ Pesquisador Cientico, Dr., IAC - Centro Avançado de Seringueira e Sistema Agroorestais; ${ }^{5}$ Pesquisador Cientico, Dr., IAC - Centro de Grãos e Fibras.

RESUMO: Apesar da conhecida plasticidade da cultura do amendoim, a densidade populacional e o arranjo são fatores que podem afetar a sua produtividade. Objetivou-se com o presente trabalho avaliar o efeito de densidades populacional e arranjos de plantio na produtividade de dois cultivares comerciais de amendoim rasteiro em Pindorama-SP, safra 2016/17. Utilizou-se as cultivares IAC OL3 e IAC 503 no delineamento experimental em blocos casualizados, em esquema fatorial 4 (densidades: 12, 18, 26 e 36 sementes por metro de linha) X 2 (linhas simples e linhas duplas), com quatro repetições, totalizando 8 tratamentos. Aos 120 e aos 135 DAS foi realizado o arranquio e inversão da cultivar IAC OL3 e IAC 503, respectivamente, em seguida foram trilhadas para a determinação da produtividade de vagens. Os cultivares de amendoim IAC OL3 e IAC 503 apresentam respostas semelhantes. Há aumento significativo na produtividade de vagens com o aumento da densidade de plantas. Os arranjos de plantio não influenciam a produtividade de vagens.

Palavras-chave: Arachis hypogaea, estande, linha simples, linha dupla.

\section{INTRODUÇÃO}

O amendoim (Arachis hypogaea L.) é uma oleaginosa de importância mundial, razão por que é responsável $10 \%$ da produção mundial de óleo comestível e o quinto mais consumido, com produção superior a quatro milhões de toneladas (GODOY et. al. 2004). O Estado de São Paulo destaca-se na produção brasileira de amendoim, como maior produtor nacional, com aproximadamente $93 \%$ da área plantada e quase $95 \%$ de toda a produção nacional (CONAB, 2018).

Observa-se na cultura do amendoim característica de plasticidade, ou seja, a planta possui mecanismos fisiológicos que lhe conferem a capacidade de se desenvolver em ambientes adversos, como solos de baixa fertilidade e clima pouco favorável para cultivo, por meio de modificações na morfologia e na produção da planta (NAKAGAWA et al., 1994).

Assim, a densidade e o espaçamento entre plantas devem ser arranjados de modo a aumentar os ganhos de produtividades das culturas. Menores espaçamentos em uma mesma população 
proporcionam melhor distribuição espacial das plantas na área, com maior aproveitamento da radiação solar, pois permitem a redução da densidade de plantas nas linhas (SMIDERLE et al., 2016). Plantas distribuídas de forma desuniforme implicam aproveitamento ineficiente dos recursos disponíveis, como luz, água e nutrientes (SMIDERLE et al., 2017).

Objetivou-se com o presente trabalho avaliar o efeito de densidades populacional e arranjos de plantio na produtividade de dois cultivares comerciais de amendoim rasteiro em Pindorama-SP, safra 2016/17.

\section{MATERIAL E MÉTODOS}

O experimento foi conduzido na Apta Regional - Polo Centro Norte, vinculado a Agência Paulista de Tecnologia do Agronegócio, pertencente à Secretaria da Agricultura e Abastecimento do Estado de São Paulo, localizado no município de Pindorama, SP. A área experimental tem solo caracterizado como argissolo eutrófico vermelho-amarelo, considerado profundo, com horizonte A arenoso e horizonte B textural com alta fertilidade e topografia plana. Conforme classificação de Köppen, o clima enquadra-se no tipo Aw, definido como tropical úmido com estação chuvosa no verão e seca no inverno.

Utilizou-se as cultivares consideradas alto oleicas, IAC OL3 e IAC 503, do programa de melhoramento genético do IAC (Instituto Agronômico de Campinas), recomendadas para as regiões, devido sua estabilidade e adaptabilidade. As sementes foram produzidas na safra 2015/2016 e possuíam $92 \%$ de germinação mínima para os ambos os cultivares. O delineamento experimental foi em blocos casualizados, em esquema fatorial $(4 \times 2)$, com quatro repetições. O primeiro fator correspondeu as densidades de semeadura: 12, 18, 26 e 36 plantas por metro de linha, o segundo fator correspondeu aos arranjos espaciais em linhas simples e linhas duplas, totalizando 8 tratamentos. $\mathrm{O}$ arranjo em linhas simples foi obtido através da semeadura no espaçamento de $0,90 \mathrm{~m}$ entre linhas. Já o arranjo em linhas duplas foi obtido através do espaçamento de $0,17 \mathrm{~m}$ entre as linhas simples e $0,73 \mathrm{~m}$ entre as linhas duplas. Cada parcela foi constituída de quatro linhas simples ou duplas de 10 metros cada, num total de $36 \mathrm{~m}^{2}$. Como área útil foi considerado $9 \mathrm{~m}^{2}$, resultante da exclusão de duas linhas $\left(1^{\mathrm{a}}\right.$ e $\left.4^{\mathrm{a}}\right)$. Aos 120 DAS foi realizado o arranquio e inversão da área útil das parcelas com a cultivar IAC OL3 e aos 135 DAS, com a cultivar IAC 503. As plantas permaneceram três dias no processo de cura em seguida foram trilhadas para a determinação da produtividade de vagens $\left(\mathrm{kg} \mathrm{ha}^{-1}\right)$.

Os dados obtidos foram submetidos à análise de variância (ANOVA) e as médias comparadas pelo teste de Tukey $(\mathrm{p}>0,05)$. 
16 e 17 de agosto de 2018, centro de convenções da FCAV/UNESP - Câmpus de Jaboticabal, SP

\section{RESULTADOS E DISCUSSÃO}

A análise de variância demonstrou haver diferença significativa na produtividade entre os tratamentos com diferentes densidades de semeadura, enquanto que não houve diferença significativa para os padrões de semeadura e para interação entre os fatores analisados (Tabela 1).

Observa-se também na Tabela 1 que houve, para os dois cultivares avaliados (IAC OL3 e IAC 503), aumento significativo na produtividade com o aumento da densidade de plantas. Em pesquisas conduzidas por GOPALASWARNY et al. (1979), concluiu que, pelo simples fato de aumentar a densidade de semeadura, observa-se aumento na população final de plantas resulta assim em aumento na produtividade, fato verificado neste experimento. Logo, ROMANINI JUNIOR (2007), concluiu que existe relação inversa entre densidade de semeadura e a produtividade.

Quanto ao efeito do arranjo de plantio sobre a produtividade das cultivares IAC OL3 e IAC 503, não houve diferença significativa entre linha simples e linhas duplas (Tabela 1).

Tabela 1: Produtividade das cultivares IAC OL3 e IAC 503 em função de densidades de populacional e arranjos de plantio no município de Pindorama-SP. Safra 2016/17.

\begin{tabular}{|c|c|c|c|}
\hline \multirow{2}{*}{$\begin{array}{c}\text { Densidade de populacional } \\
\text { Plantas/metro }\end{array}$} & \multicolumn{2}{|c|}{ Pindorama } & \\
\hline & IAC OL3 & IAC 503 & \\
\hline 12 & $1.979,75 \mathrm{~d}$ & $1.814,62 \mathrm{~d}$ & $\mathrm{~d}$ \\
\hline 18 & $3.094,87 \mathrm{c}$ & $3.652,25 \mathrm{c}$ & c \\
\hline 26 & $4.108,37 \mathrm{~b}$ & $4.092,37 \mathrm{~b}$ & $b$ \\
\hline 36 & $5.593,75 \mathrm{a}$ & $5.702,25 \quad \mathrm{a}$ & $a$ \\
\hline DMS (5\%) & 318,35 & 333,61 & \\
\hline Teste F & $361,73 * *$ & $356,78 *$ & $* *$ \\
\hline \multicolumn{4}{|l|}{ Arranjos } \\
\hline Linha simples & $3.730 \mathrm{a}$ & $3.832 \mathrm{a}$ & $\mathrm{a}$ \\
\hline Linha dupla & $3.659 \mathrm{a}$ & $3.799 \mathrm{a}$ & $a$ \\
\hline DMS (5\%) & 167,95 & 176,01 & \\
\hline Teste $F$ & $0,78 \mathrm{~ns}$ & $0,15 \mathrm{n}$ & $\mathrm{ns}$ \\
\hline Interação (DS x PL) & $0,04 \mathrm{~ns}$ & $0,34 \mathrm{n}$ & $\mathrm{ns}$ \\
\hline Média geral & 3.694 & 3.815 & \\
\hline $\mathrm{CV}(\%)$ & 6,18 & 6,27 & \\
\hline
\end{tabular}

Médias seguidas pela mesma letra na coluna não diferem entre si pelo teste de Tukey $(p>0,05)$. NS: Não significativo; $* *$ Significativo a $1 \%$ de probabilidade.

Os dados obtidos mostram que, para os dois cultivares, os arranjos de plantio não apresentaram efeito significativo sobre a produtividade de vagens, concordando com os dados obtidos por BHOITE \& NIMBALKAR (1995) e discordando com os obtidos por NANDANIAET al. (1992). DESHPANDE et al. (1986) observaram que existe uma tendência de maior produção no espaçamento 
16 e 17 de agosto de 2018, centro de convenções da FCAV/UNESP - Câmpus de Jaboticabal, SP

duplo, resultando em um arranjo mais adensado de plantas. Já PEIXOTO et al. (2008) observaram o aumento do volume de vagens com redução do espaçamento entre plantas.

Na Figura 1 observa-se que para a densidade de 18 sementes por metro, o cultivar IAC 503 obteve maior produtividade $\left(4.020,87 \mathrm{~kg} \mathrm{ha}^{-1}\right)$ quando comparado ao cultivar IAC OL3 $(3.587,50 \mathrm{~kg}$ $\left.\mathrm{ha}^{-1}\right)$, tal constatação pode ser justificada pelo fato do cultivar IAC 503 possui ciclo mais longo, tendo como consequência, maior capacidade de vegetal e reproduzir sem sofrer com estreses bióticos e abióticos.

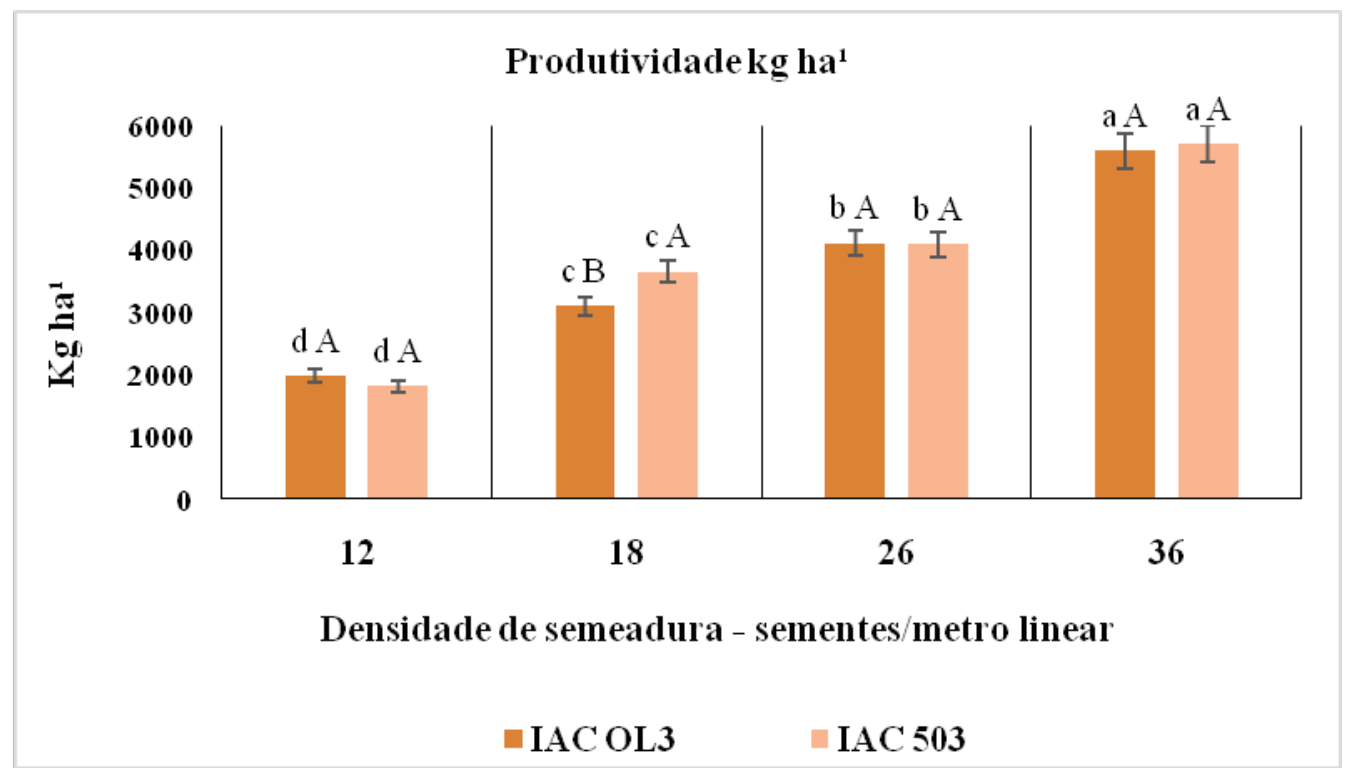

Figura 3: Produtividade $\left(\mathrm{kg} \mathrm{ha}^{-1}\right)$ de amendoim em casca dos cultivares IAC OL3 e IAC 503 influenciada pela densidade de semeadura, município de Pindorama-SP.

\section{CONCLUSÃO}

Os cultivares de amendoim IAC OL3 e IAC 503 respondem de maneira semelhantes aos fatores estudados neste trabalho.

Há aumento significativo na produtividade de vagens com o aumento da densidade de plantas até 36 plantas por metro.

Os arranjos de plantio não influenciam a produtividade de vagens.

\section{REFERENCIAS BIBLIOGRÁFICAS}

CONAB- Companhia Nacional de Abastecimento. Acompanhamento da safra brasileira 2018. v. 5 Safra 2017/18 - n. 10 - Décimo levantamento julho 2018. Disponível em: $<$ https://www.conab.gov.br/info-agro/safras/graos>. Acesso em 01/07/2018.

DESHPANDE, S.L. Effectofspacingandzincapplicationonyieldofgroundnut (Arachishypogaea). The Madras AgriculturalJournal, Coimbratore, v. 73, n. 9, p. 521-523, 1986. 
GODOY, I.J.; MORAES, S.A.; ZANOTTO, M.D.; SANTOS, R.C. Melhoramento do Amendoim. In: BORÉM, A. (Ed.). Melhoramento de espécies cultivadas. 2.ed. Viçosa: Universidade Federal de Viçosa, 2004. p.51-102.

GOPALASWANY, N.; ELANGOVAN, R.; RAJAH, C. Agronomic and economic optimum plant densities for rainfed groundnut. Indian Journal of Agricultural Scienses, NewDelhi, v.49, n.1, p.1721, 1979.

NAKAGAWA, J.; LASCA, D.H.C.; NEVES, J.P.S.; NEVES, G.S.; SILVA, M.N.; SANCHES, S.V.; BARbOSA, V.; ROSSETO, C.A.V. Densidades de plantas e produção de amendoim. Scientia Agrícola, Piracicaba, v.57, n.1, p.67-73, 2000.

PEIXOTO, C. P.; GONCAlveS, J. A.; PEIXOTO, M. F. S.P.; CARMO, D. O. Características agronômicas e produtividade de amendoim em diferentes espaçamentos e épocas semeadura no Recôncavo Baiano. Bragantia, v. 67, n. 3, p. 563-568, 2008.

ROMANINI JUNIOR, A. Influência do espaçamento de plantas no crescimento, produtividade e rendimento do amendoim rasteiro, cultivar Runner IAC 886.p. 38- 39, 2007. (Dissertação de Mestrado) - Faculdade de Ciências Agrárias e Veterinárias; Universidade Estadual Paulista, Jaboticabal, 2007.

SMIDERLE, O.J.; SOUZA, A.G.; GIANLUPPI, D.; GIANLUPPI, V. Variabilityamong BRS 8381 soybean (Glycinemax (L.) Merrill.) yieldcomponentsunderdifferentliming rates andsowingdensitieson a savanna in Roraima, Brazil. Revista Colombina Investigação Agroindustriales, v.2, n.3, p- 49-55, 2016.

SMIDERLE, O.J.; LIMA-PRIMO, H.E.; BARBOSA, H.D.; SOUZA, A.G. Efeito da desfolha em diferentes estádios fenológicos do feijão-caupi sobre componentes de produção. Revista Ciência Agronômica, v. 48, n. 5 (Especial), p. 231-242, 2017. 